\title{
Water induces autocrine stimulation of tumor cell killing through ATP release and $\mathrm{P} 2$ receptor binding
}

\author{
N Selzner ${ }^{1,3}, M$ Selzner ${ }^{1,3}, \mathrm{R}$ Graf ${ }^{1}, \mathrm{U}$ Ungethuem ${ }^{1}$, JG Fitz $^{2}$ \\ and P-A Clavien ${ }^{\star, 1}$ \\ ${ }^{1}$ Department of Visceral and Transplantation Surgery, Zurich University \\ Hospital, Zurich, Switzerland \\ 2 Department of Medicine, University of Colorado Health Science Center, \\ Denver, CO, USA \\ 3 These authors contributed equally to this work \\ * Corresponding author: P-A Clavien, Department for Visceral Surgery and \\ Transplantation, University of Zurich, Rämistr. 100, 8091 Zürich, Switzerland \\ Tel: +411-255-3300; Fax: +411-255-4449; E-mail: Clavien@chir.unizh.ch
}

Received 19.1.04; revised 17.6.04; accepted 20.7.04; published online 1.10.04 Edited by M Piacentini

\section{Abstract}

Although exposure of cells to extreme hypotonic stress appears to be a purely experimental set up, it has found an application in clinical routine. For years, surgeons have washed the abdominal cavity with distilled water to lyse isolated cancer cells left after surgery. No data are available supporting this practice or evaluating the potential mechanisms of cell injury under these circumstances. Recent evidence indicates that increases in cell volume stimulate release of adenosine triphosphate and autocrine stimulation of purinergic (P2) receptors in the plasma membrane of certain epithelial cell types. Under physiological conditions, purigenic stimulation can contribute to cell volume recovery through activation of solute efflux. In addition, adenosine triphosphate-P2 receptor binding might trigger other mechanisms affecting cell viability after profound hypotonic stress. This study demonstrates a novel pathway of cell death by apoptosis in human colon cancer cells following a short hypotonic stress. This pathway is induced by transitory cell swelling which leads to extracellular release of adenosine triphosphate (ATP) and specific binding of ATP to P2 receptors (probably P2X7). Extracellular ATP induced activation of caspases 3 and 8 , annexin $V$, release of cytochrome $c$, and eventually cell death. The effect of ATP can be blocked by addition of (i) apyrase to hydrolyse extracellular ATP and (ii) suramin, a P2 receptor antagonist. Finally, (iii) gadolinium pretreatment, a blocker of ATP release, reduces sensitivity of the cells to hypotonic stress. The adenosine triphosphate-P2 receptor cell death pathway suggests that autocrine/paracrine signaling may contribute to regulation of viability in certain cancer cells disclosed with this pathway.

Cell Death and Differentiation (2004) 11, S172-S180.

doi:10.1038/sj.cdd.4401505

Published online 1 October 2004

Keywords: ATP; colon cancer cells; P2 receptor; apoptosis

Abbreviations: ATP, adenosine triphosphate; LDH, lactate deshydrogenase; Gadolinium, $\mathrm{Gd}^{3}$

\section{Introduction}

Cell volume is maintained within a narrow physiologic range despite large changes in solute transport and extracellular osmolalities. However, isolated cells undergo lysis after prolonged exposure to hypotonic media. This vulnerability of cells to a hypotonic milieu has been used occasionally in patients. For example, for years surgeons have washed the abdominal cavity with distilled water with the intent of lysing isolated cancer cells left after surgery. ${ }^{1,2}$ No data are available supporting this practice or evaluating the potential mechanisms of cancer cell injury related to hypotonic exposure.

In most epithelial cells, transient exposure to hypotonic media stimulates compensatory mechanisms such as opening of ion channels which mediate solute efflux and restoration of cell volume toward basal values. Hypotonic challenge and cell swelling also affect numerous regulators of cell metabolism and transport in a cell type-specific manner. Recent evidence indicates that release of adenosine triphosphate (ATP) to the extracellular space is necessary in certain cell types to recover from swelling. ${ }^{3}$ ATP in the extracellular space, functions as an autocrine signal by binding to membrane P2 receptors. ${ }^{4,5}$ The resulting efflux of solutes favors passive water loss, thereby restoring cell volume. Notably, there are a number of P2 receptor subtypes which are activated by extracellular ATP. Thus, a broad range of cellular functions are targeted by ATP/P2 receptors. ${ }^{6}$ Moreover, most cells exhibit more than one P2 receptor type, including members of the P2X family of ligand-regulated cation channels and the P2Y family of G protein coupled receptors. Consequently, extracellular ATP could elicit more than one response depending on the $\mathrm{P} 2$ receptor subtype expressed and could trigger mechanisms affecting cell viability after hypotonic shock.

We tested in human colon cancer cells, the effects of a short period of hypotonic shock on cell viability and related mechanisms of injury. We first studied cell volume recovery after a short exposure to distilled water and investigated subsequent viability. We then measured ATP release and blocked the ATP-P2 receptor signaling using three different agents with a focus on the induction of the apoptotic pathway. Our results demonstrate a new pathway of cell death related to temporary cell swelling involving the release of extracellular ATP and selective binding to ATP-P2 receptors, most likely to the P2X7 receptor. This autocrine or paracrine purinergic signaling triggers activation of caspase 8 , release of cytochrome $c$ followed by caspase 3 , and causes cell death by apoptosis within $24 \mathrm{~h}$.

\section{Results}

\section{Hypotonic stress decreases cell viability}

Abdominal lavage with distilled water is presumed to induce cell death. To assess whether this can be detected in culture 
cell models, the effects of hypotonic exposure on cell viability were assessed in three different human colon cancer cell lines (SW403, HCT 116 and Colo), chosen for their preserved phenotype and their expression of human colon cancer antigens. As controls, two different nontumor cells (human fibroblasts and primary rat hepatocytes) were evaluated in parallel.

To establish the effect of short hypotonic stress on colorectal cell viability, we exposed three tumor cells to distilled water for various periods of time ( 1,3 and $5 \mathrm{~min}$ ). Cells were returned afterwards to their standard isotonic culture medium. The viability of cells was detected by Trypan blue uptake after $24 \mathrm{~h}$. Our results demonstrated a dramatic decrease in viability of cells $24 \mathrm{~h}$ after 1,3 or $5 \mathrm{~min}$ of exposure to distilled water. As the effect on cell viability was intense with either period of exposure, we performed further experiments with only $1 \mathrm{~min}$ of exposure to distilled water (Figure 1a). Next, we evaluated cell viability at three different times points after $1 \mathrm{~min}$ of exposure to distilled water. Only minimal cell death was detected in all groups after $4 \mathrm{~h}$ incubation. Afterwards, all three cell lines challenged with pure water exhibited a dramatic decrease in viability in a timedependent manner after 12 and $24 \mathrm{~h}$ incubation. Finally, we determined the effect of (i) gradual hypotonic dilution $(0.20$, 0.45 and $0.75 \%$ ), (ii) isotonic $(0.9 \%)$ saline solution and (iii) hypertonic saline solution (1.8\%) on cell viability $24 \mathrm{~h}$ after 1 min of incubation with either of these solutions. Only minimal decreases in viability were detectable in all three cell lines after exposure to $0.20,0.45,0.75,0.9$, or $1.8 \%$ saline solutions. The results for the most sensitive cell line SW403 are presented in Figure $1 \mathrm{~b}$. While long exposure $(24 \mathrm{~h})$ to hypertonic media can affect cell viability ${ }^{8,9}$ our results indicate that a short hypertonic challenge is harmless. As results were similar for the other two colon cancer cell lines, these data are not shown. In contrast to colon cancer cells, only minimal decreases in viability (10 and $5 \%$ ) were detectable in human fibroblasts and rat hepatocytes $24 \mathrm{~h}$ after exposure to $1 \mathrm{~min}$ of distilled water (Figure 1c, $n=5$ for each experiments).

\section{Hypotonic shock induces temporary cell swelling followed by release of endogenous ATP}

To assess the effect of cell volume changes on the subsequent ATP release, we first determined the cell volume after hypotonic stress. Mean cell volumes were measured during hypotonic (distilled $\mathrm{H}_{2} \mathrm{O}, 0.20$ or $0.45 \%$ ) and isotonic ( $0.9 \%$ saline solution) challenge at 0,30 and $60 \mathrm{~s}$. We further evaluated cell volume recovery after 2, 5 and $20 \mathrm{~min}$ after replacement of the media by culture medium (Figure 2). Cells underwent a three-fold increase in volume within $30 \mathrm{~s}$ of exposure to distilled $\mathrm{H}_{2} \mathrm{O}$, and a five-fold increase after 1 min compared to the control group (cells exposed to isotonic media). Cells exposed to $1 \mathrm{~min}$ of 0.20 and $0.45 \%$ hypotonic media resulted in 1.4- and 2-fold increase of volume compared to the control group. Recovery to the initial volume occurred within $20 \mathrm{~min}$ after the hypotonic challenge. To evaluate the possibility that hypotonic exposure may cause cell lysis by necrosis, lactate dehydrogenase (LDH) release into the medium was assessed. A 1 min challenge with water
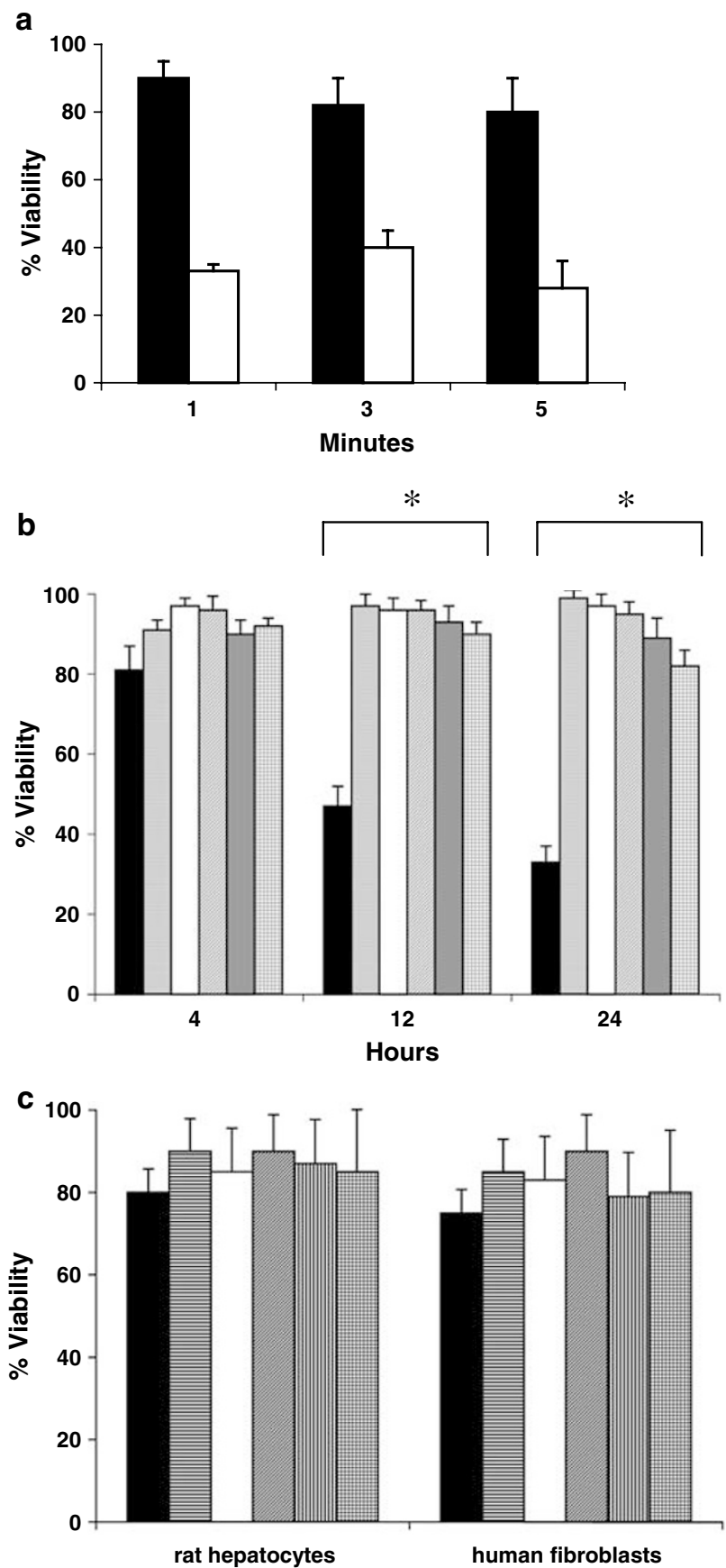

Figure 1 Effect of exposure time and hypotonic shock on cell viability. (a) SW403 cells were exposed for 1,3 or 5 min to distilled water $(\square)$ or isotonic solution $(0.9 \%$ saline $)$ followed by restitution in normal cell medium (DMEM). Cell viability was evaluated by trypan blue staining at $24 \mathrm{~h}$ after hypotonic stress $(n=5$ in each group). (b) SW403 cells were exposed for $1 \mathrm{~min}$ to distilled water ( $)$ or different concentrations of saline solution $(0.200 .45 \square, 0.75,0.9$ or $1.8 \%$ ) followed by restitution in normal cell media (DMEM). Cell viability was evaluated by trypan blue staining at 4,12 and $24 \mathrm{~h}$ after osmotic stress. Hypotonic stress by distilled water induced 50 and $35 \%$ of SW403 cell death after 12 and $24 \mathrm{~h}$ incubation (a) $(n=5$ in each group, $P<0.001$, ANOVA; ${ }^{*}=P<0.001$, Bonferroni post hoc). (c) Rat hepatocytes or human fibroblasts were treated similarly and viability was assessed $24 \mathrm{~h}$ after incubation in normal cell medium ( $n=5$ in each group) 


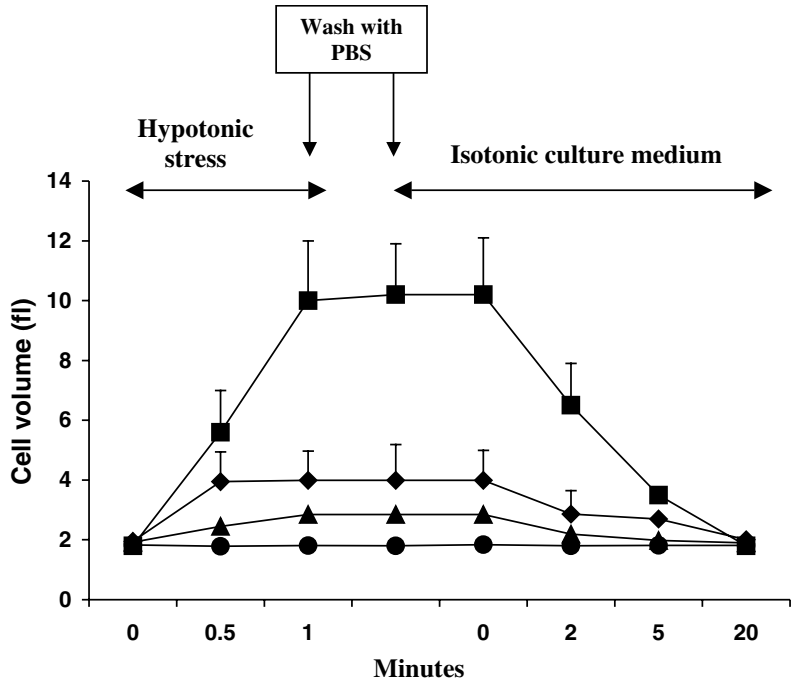

Figure 2 Evaluation of cell volume during and after hypotonic stress. Incubation in distilled water ( $\mathbf{\square}$ ) induced a five-fold increase in cell volume, while $0.20 \%(\mathbf{\Delta})$ and $0.45 \%(\bullet)$ of saline solution resulted in respectively, 1.4 and two-fold increase in cell volume. Complete recovery of cell volume occurred within $20 \mathrm{~min}$ after reincubation in culture medium (DMEM). Control cells $(\boldsymbol{\bullet})$ exposed to isotonic solution $0.9 \%$ followed by incubation in culture media demonstrated no difference in size ( $n=5$ in each group)

resulted in a 1.2-fold increase in LDH levels compared to control cells (Figure 3a). This suggests that a short exposure to water causes only minimal cell lysis even though $24 \mathrm{~h}$ later a considerable population of the cells is nonviable. To further demonstrate beyond which length of exposure cells challenged with water will be lysed, we prolonged exposure to water up to $30 \mathrm{~min}$. Serial measurement of LDH in the media demonstrated that only exposure above $15 \mathrm{~min}$ to distilled water (Figure $3 b$ ) was associated with significant increases in $\mathrm{LDH}$ levels and cell lysis.

Since it has been shown that cell volume was controlled by extracellular ATP, we tested whether ATP was released after a brief hypotonic shock. ATP release was measured by bioluminescence luciferase assay. As shown in (Figure 4a), the concentration of ATP from SW403 cells under basal condition was approximately $40 \mathrm{nM}$ suggesting that there is a constitutive release of ATP. Hypotonic challenge with distilled water resulted in an 8.7-fold increase in extracellular ATP concentration $(350 \mathrm{nM})$ within $2 \mathrm{~min}$ following exposure to distilled water. Hypotonic challenge with 0.20 and $0.45 \%$ of saline solution at the same time points, that is $2 \mathrm{~min}$ after exposure to water had intermediate effects resulting in a three- and five-fold increase in extracellular ATP (120 and $200 \mathrm{nM}$ ), respectively. Thus, cell volume increases are associated with a proportional increase in ATP release, but cell death is observed only after exposure to distilled water. To test whether the same principle of ATP release could be observed in nontumoral cells, we repeated the same experiments with human fibroblasts, HFF5 cells. As shown in Figure $4 b$ the concentratiom of ATP released from HFF5 cells under basal condition was approximately $9.5 \mathrm{nM}$. Hypotonic challenge with distilled water resulted in a two-fold increase in extracellular ATP concentration $(20 \mathrm{nM})$ within $2 \mathrm{~min}$ after exposure to water. Similarly, hypotonic challenge with 0.20
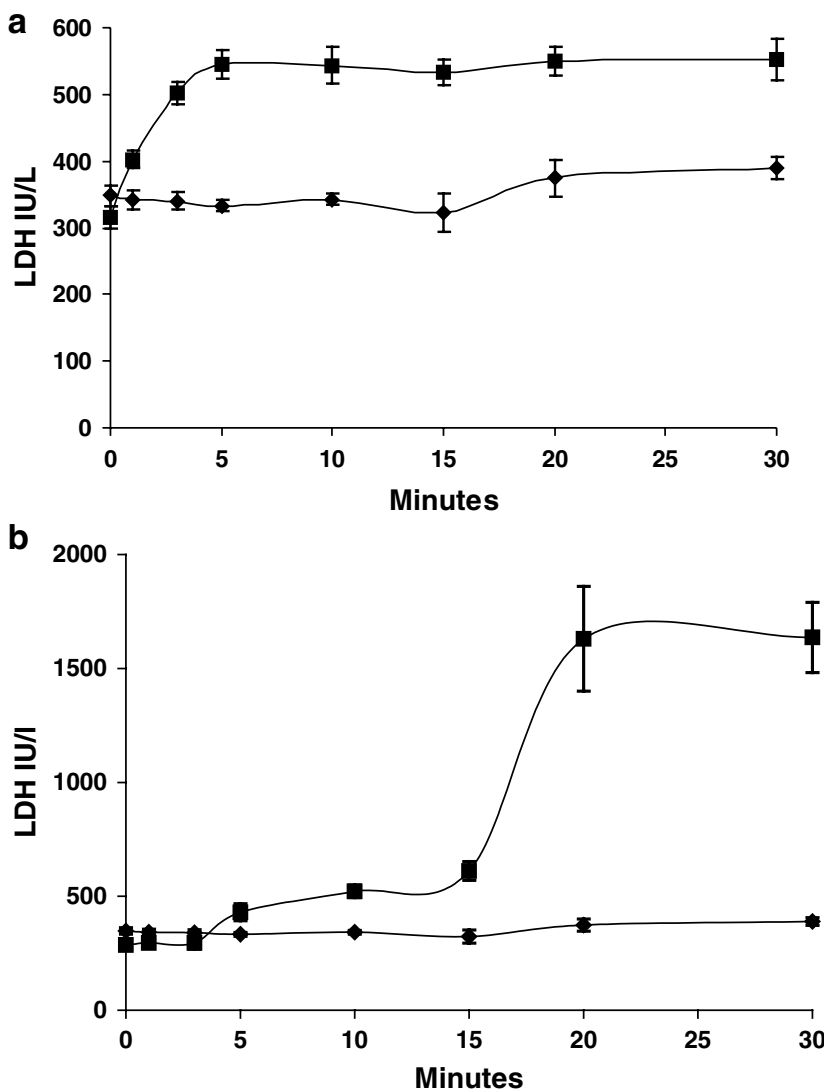

Figure $3 \mathrm{LDH}$ release from cells exposed to hypotonic challenge. (a) At $1 \mathrm{~min}$ of exposure to distilled water ( $\mathbf{\square})$ followed by incubation in isotonic $(0.9 \%)$ saline solution, induced a moderate (1.2-fold) increase in LDH level compared to control cells ( ) incubated in isotonic solution. (b) Prolonged exposure $(60 \mathrm{~min})$ to distilled water $(\mathbf{\square})$ induced increased LDH levels above $15 \mathrm{~min}$ of incubation. In contrast, no LDH release has been observed in control cells incubated for $30 \mathrm{~min}$ with isotonic solution $(\bullet)(n=5$ in each group). (Note that $Y$ scale is different between the graphs (a) and (b))

and $0.45 \%$ of saline solution had intermediate effects in ATP release (14 and $19 \mathrm{nM})$, respectively.

To determine the kinetics of ATP-release, SW403 cells were monitored using a temperature-controlled Turner model TD20/20 luminometer. After exposure to $1 \mathrm{~min}$ of hypotonic stress followed by incubation in culture media for another minute, the cells released ATP at a much higher rate compared to the control group treated with 0.9 saline (Figure 5). The ATP release gradually declined within $8 \mathrm{~min}$ of incubation in culture medium (Figure 5).

\section{Hypotonic stress causes cell death through a caspase and mitochondria-dependent mechanism}

Additional studies were performed to identify the mechanisms of cell death following the hypotonic challenge. The delayed reduction of cell viability together with the low LDH release after $1 \mathrm{~min}$ of hypotonic stress suggested that the cells might undergo an apoptotic pathway. Various markers of apoptosis were evaluated including caspase 8 activity, caspase 3 activity, cytochrome $c$ release, Annexin $\mathrm{V}$ binding (translocation of phosphatidylserine to the outer surface of the 
a

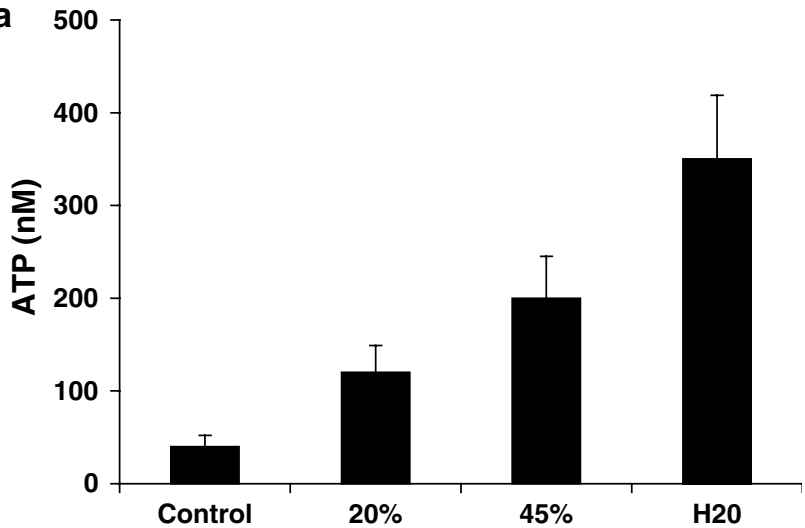

b

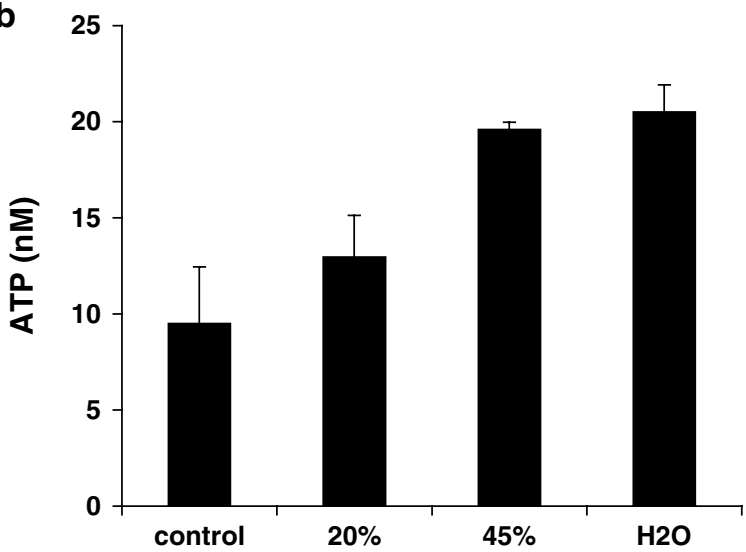

Figure 4 ATP release from the human colon carcinoma cell line (SW403) and normal cells (human fibroblasts, HFF5) after hypotonic challenge. (a) Brief exposure to distilled water resulted in a dramatic ATP release from SW403 cells (eight-fold) into the extracellular medium compared to the baseline condition. A decrease of osmolality to 0.45 and $0.20 \%$ induced a stepwise release of ATP (three and five-fold) compared to the control group ( $n=5$ at each time point). These data were collected $2 \mathrm{~min}$ after exposure to distilled water. (b) Normal cells (HFF5) display a two-fold increase in ATP release in extracellular media $2 \mathrm{~min}$ after exposure to $1 \mathrm{~min}$ of distilled water. A decrease of osmolality to 0.45 and $0.20 \%$ resulted in a stepwise release of ATP ( $n=3$ at each time point)

cytoplasmic membrane, an early feature of apoptosis), and in situ TUNEL assay (double-strand DNA fragmentation).

The transfer of phosphatidyl serine to the outer membrane surface is an early event in apoptosis. Annexin V binds to this membrane and is used as an indicator of apoptosis. Counterstaining with propidium iodide allows detection of cells with membrane damage and concomitant staining of Annexin $\mathrm{V}$ in the inner membrane indicates necrosis or late stage of apoptosis. While Annexin $\mathrm{V}$ binding was observed in only a minority of cells exposed to $0.9 \%$ saline $(<20 \%$ ), Annexin V expression was documented after $1 \mathrm{~h}$ in most cells $(70 \%)$ subjected to $1 \mathrm{~min}$ of hypotonic shock (Figure 6a). At later time points, more cells developed propidium iodide staining indicating a progression of apoptosis in these cells (not shown).

Similarly, the activities of caspase 8 and 3 and the release of cytochrome $c$ from mitochondria into the cytoplasm were elevated by hypotonic exposure. While only minimal background activity was detectable in cells exposed to physiologic saline, caspase 8 and 3 activities demonstrated a seven-fold

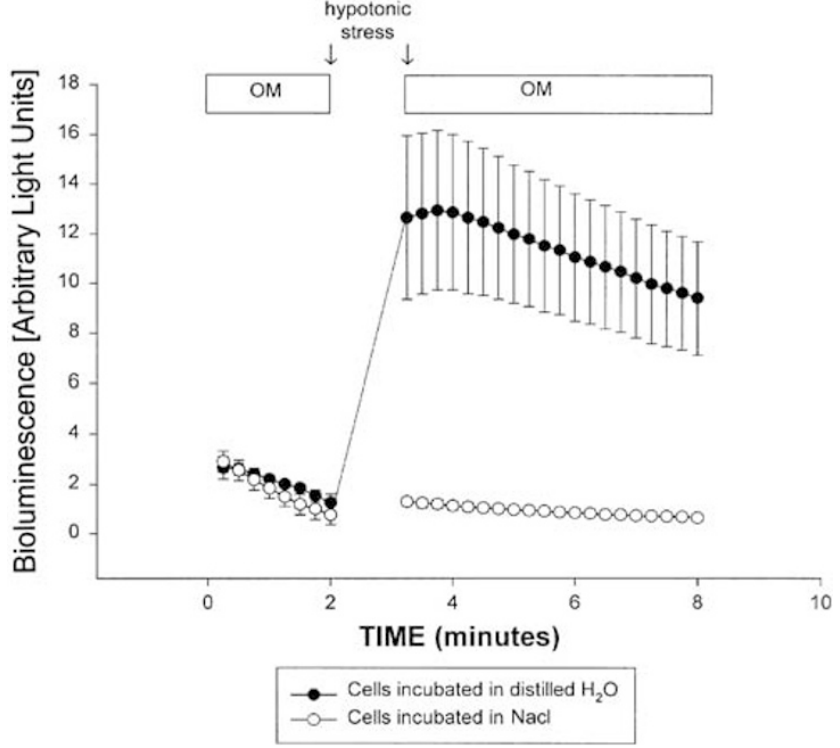

Figure 5 ATP release from human colon carcinoma cell line during and after hypoosmotic challenge. Brief exposure to distilled water $(\bullet)$ resulted in a dramatic ATP release into the extracellular medium. In contrast, low ATP release was detected in cells challenged with $0.9 \%$ saline solution $(\square)(n=5$ at each time point). $\mathrm{OM}=$ optic medium

increase $1 \mathrm{~h}$ (Figure 6b) and $4 \mathrm{~h}$ (not shown) after hypotonic challenge. Cytochrome $c$ release from mitochondria, a standard marker of apoptosis was significantly increased as early as $1 \mathrm{~h}$ (Figure 6c) after hypotonic shock.

DNA double-strand breakage, a late marker of apoptosis, was determined by TUNEL staining. While cells exposed to $0.9 \%$ saline demonstrated minimal TUNEL staining $(<5 \%)$, the brief period of hypotonic stress induced a time-dependent increase in the number of TUNEL-positive cells. At $24 \mathrm{~h}$ after $1 \mathrm{~min}$ hypotonic challenge, $95 \%$ of the tumor cells were TUNEL positive indicating that nearly all cells had progressed to a late phase of apoptosis (Figure 6d).

\section{ATP release and ATP2 receptor stimulation induces cell death following hypotonic stress}

Previous studies demonstrated that volume-sensitive ATP release can coordinate cell volume and membrane permeability through activation of $\mathrm{P} 2$ receptors. ${ }^{3}$ Therefore, we speculated that an analogue signaling pathway might be involved in induction of apoptosis following hypotonic stress. To test this hypothesis, prurigenic signaling was interrupted by exposure to (i) apyrase to cleave extracellular ATP, (ii) suramin to block P2 receptors or (iii) Gadolinium $(\mathrm{Gd})^{3}$ to inhibit ATP release. ${ }^{7}$ If extracellular ATP was involved in the apoptotic response, these agents would be anticipated to increase cell viability.

Both apyrase $(10 \mathrm{U} / \mathrm{ml})$ and suramin $(1 \mathrm{mM})$ added to the culture media during and after hypotonic stress dramatically improved cell viability (Figure 7). Eighty percent and 66\%, of cells treated, respectively, with apyrase and suramin tolerated the hypotonic shock compared to $20 \%$ in the control cells. To test the specificity of apyrase, a nonhydrolyzable P2 receptor agonist $(A T P \gamma S)$ was added to the culture media. 
Interestingly, ATP $\gamma \mathrm{S}(600 \mu \mathrm{M})$ resulted in full expression of apoptosis, suggesting that the effects of apyrase are mediated by removal of extracellular ATP (Figure 7).

Gadolinium is known to prevent ATP release. To test the effect of $\mathrm{Gd}^{3}$ it was added at various concentrations $(300,600$ and $900 \mu \mathrm{M}$ ) to the media prior to hypotonic stress. The results demonstrated that $\mathrm{Gd}^{3}$ significantly prevented cell death in a dose-dependent manner $(40,60$ and $80 \%$ with respective

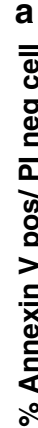

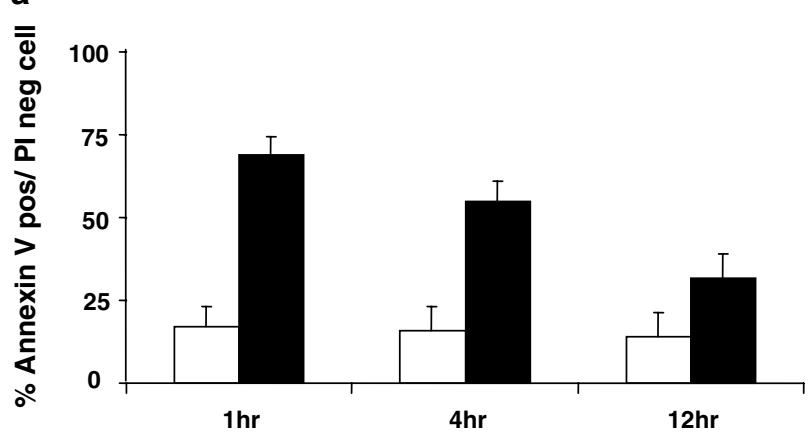

b

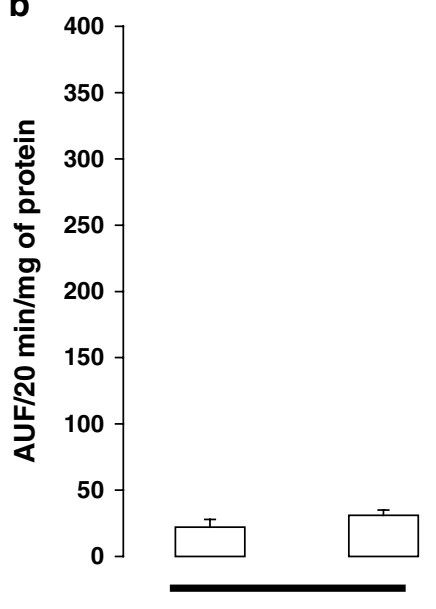

Caspases 3

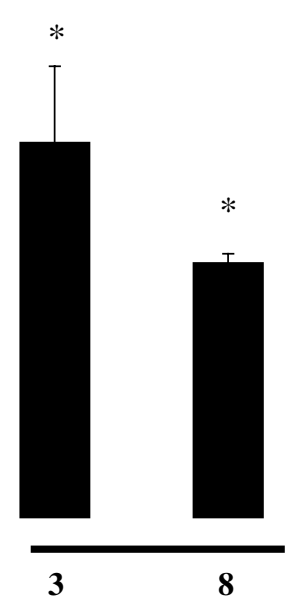

C

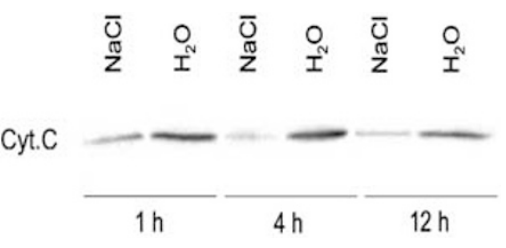

d

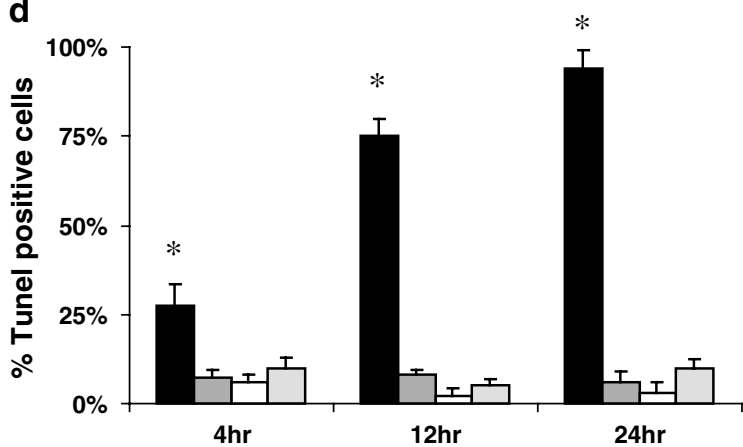

doses compared to $20 \%$ viability in control group without pretreatment with $\mathrm{Gd}^{3} . n=5$ in each group, ${ }^{\star} P<0.05$, data not shown).

Taken together, the effects of apyrase, suramin and $\mathrm{Gd}^{3}$ suggest that volume-sensitive ATP release plays a key role in induction of apoptosis following hypotonic exposure.

To provide further evidence that the direct release of ATP from cells after exposure to distilled water induces cell death, we incubated cells with ATP $\gamma S$ at a concentration similar to that observed after hypotonic shock $(350 \mathrm{nM})$ and to a lower concentration with which the viability was not expected to decrease $(200 \mathrm{nM})$. While most SW403 cells (>95\%) died after $8 \mathrm{~min}$ of exposure to $350 \mathrm{nM}$ of ATP $\gamma \mathrm{S}$, only minimal death $(<10 \%)$ was observed after exposure to $200 \mathrm{nM}$ of ATP $\gamma \mathrm{S}$ (Figure 8a). Furthermore, $24 \mathrm{~h}$ after an $8 \mathrm{~min}$ exposure

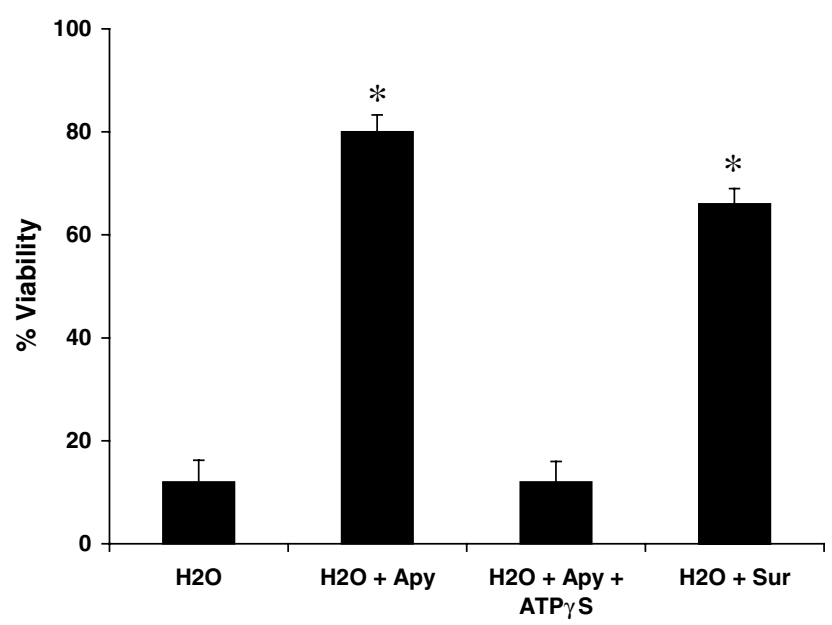

Figure 7 ATP release and P2-receptor binding induces cell death. Treatment of the tumor cells with the ATP scavenger apyrase $(10 \mathrm{U} / \mathrm{ml})$ prevented cell death after exposure to $1 \mathrm{~min}$ of hypotonic stress. The effect of apyrase was reversed by the addition of ATP $\gamma S(600 \mu \mathrm{M})$, an apyrase-resistant P2 receptor agonist. Similarly, blocking the P-2 receptor by suramin $(1 \mathrm{mM})$ decreased cell death when compared to cells treated with $\mathrm{H}_{2} \mathrm{O}$ alone $\left(n=5\right.$ in each group, $\left.{ }^{\star} P<0.01\right)$

Figure 6 Hypotonic stress causes cell death through induction of apoptosis in SW403 cells. The effect of hypotonic ( $\boldsymbol{\square}$ ) and isotonic $(\square)$ media on markers of apoptosis were determined ( $n=5$ in each group). (a) Hypotonic stress results in early Annexin V membrane binding that is detectable at $1 \mathrm{~h}, 4 \mathrm{~h}$ and $12 \mathrm{~h}$ after incubation with distilled water $(\mathbf{\square})$. Only minimal staining was detected in cells exposed to saline solution ( $\square$ ). (b) Activation of caspase 3 and 8 after 1 min exposure to distilled water $(\mathbf{\square})$ or saline $(\square)$. At $1 \mathrm{~h}$ after hypotonic stress a significant increase of caspase 3 and 8 was detected in cells exposed to hypotonic shock, when compared with cells incubated in saline solution. Similar results have also been detected at $4 \mathrm{~h}$ (data not shown). (c) Western blot of cytoplasmic cytochrome $c$ at 1,4 and $12 \mathrm{~h}$ after hypotonic challenge. A significant increase of cytochrome $c$ release into the cytoplasm was observed in cells incubated with distilled water compared to the control cells incubated with saline solution. (d) DNA fragmentation as a late marker of apoptosis was determined by Tunel staining. Cells incubated with distilled water ( $\mathbf{\square})$ demonstrated a timedependent increase of Tunel staining at 4,12 and $24 \mathrm{~h}$, with $95 \%$ of cell death within $24 \mathrm{~h}$. Cells treated with saline solution at various concentrations $(\square=0.45 \%,=0.9 \%$ and $=1.8 \%)$ did not demonstrate DNA fragmentation at any time point $(P<0.05)$ 
a
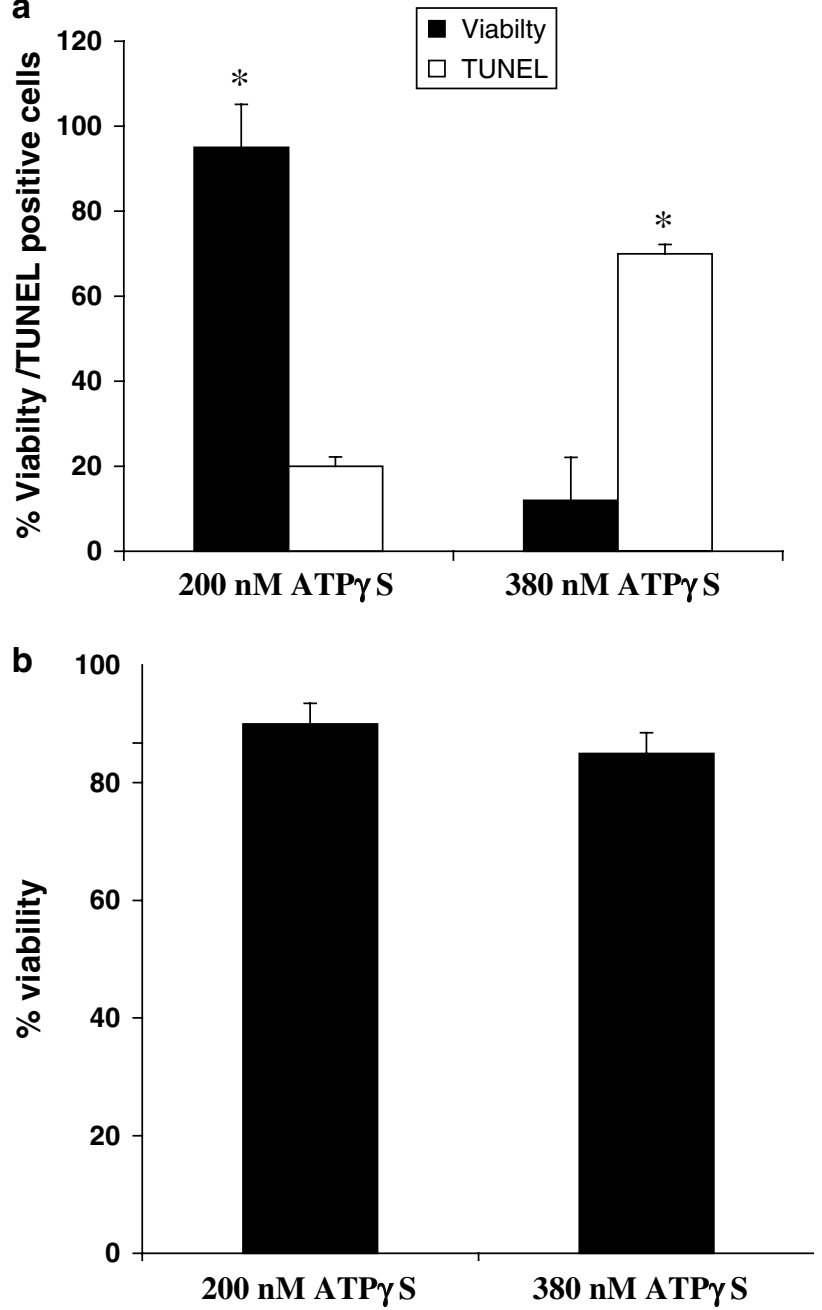

Figure 8 P2receptor agonist (ATP $\gamma \mathrm{S}$ ) induces cell death. (a) Treatment of SW403 cells with ATP $\gamma$ S at the dose of $350 \mathrm{nM}$ induced massive cell death as assessed by trypan blue and tunel staining. In contrast minimal cell death was observed in cells treated with a lower dose $(200 \mathrm{nM})$ of ATP $\gamma \mathrm{S}(n=5$ in each group, ${ }^{*} P<0.01$ ). (b) Only a minimal cell death has been observed in nontumoral cells (HFF5, human fibroblasts cells) treated with either dosage (200 or $380 \mathrm{nM}$ ) of $\operatorname{ATP} \gamma S$ ( $n=5$ in each group)

to $350 \mathrm{~nm}$ of ATP $\gamma \mathrm{S}, 70 \%$ of cells were positive for TUNEL staining compared to $20 \%$ in the control cells (Figure $8 \mathrm{a}$ ). Of note, exposure to the same condition at either doses of ATP $\gamma S$ failed to induce death in non-tumoral cells (HFF5, human fibroblast cells) (Figure 8b).

\section{Hypotonic stress induces tumor cell death through activation of $\mathrm{P} 2 \mathrm{X7}$ receptors}

Finally, to provide evidence that cell death occurs through activation of $\mathrm{P} 2$ receptors known to be cytotoxic, we measured the level of expression of P2X 7 receptors by flow cytometry. At $5 \mathrm{~h}$ after $1 \mathrm{~min}$ of exposure to distilled water, $40 \%$ of SW403 cells expressed P2X7 receptors as detected by FACS analysis. No expression has been detected in control cells challenged with isotonic solution (Figure 9a). We further determined P2X7 receptor expression at different time
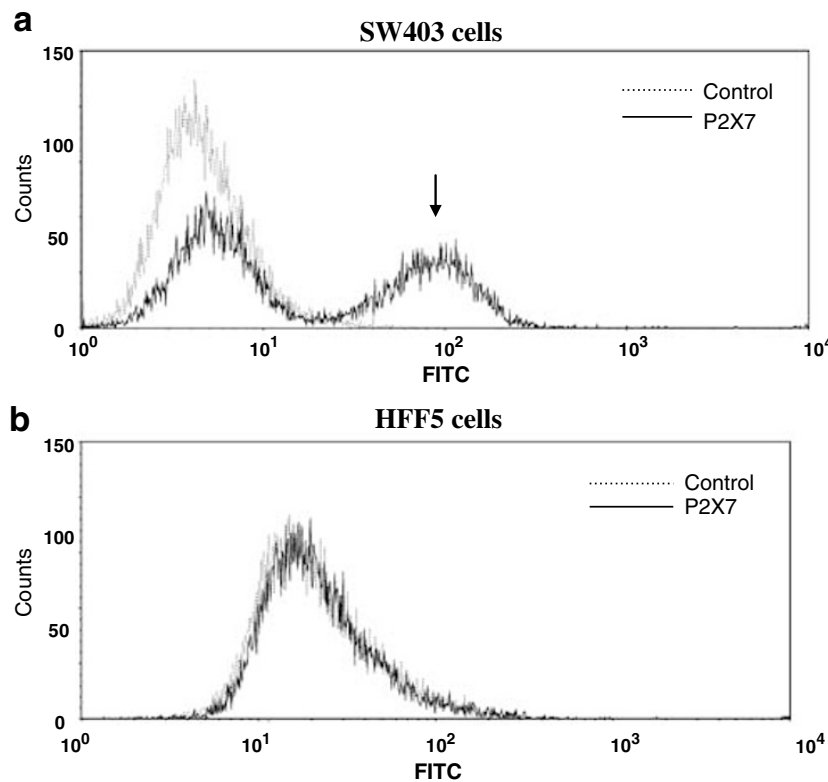

Figure 9 P2X7 receptor expression on the surface of tumoral and normal cells. (a) At $5 \mathrm{~h}$ after $1 \mathrm{~min}$ of incubation with distilled water, $40 \%$ of SW403 cells expressed P2X7 receptors at their surface as measured by flow cytometry (arrow solid line). No detection of P2X7 receptors was observed in control cells incubated with $0.9 \%$ saline for 1 min (dotted line). (b) Normal cells (HFF5) have no expression of P2X7 receptor at their surface with our without incubation with 1 min of distilled water ( $n=3$ in each group)

points $(0,5$ and $10 \mathrm{~h})$ after $1 \mathrm{~min}$ of incubation with distilled water. The presence of the receptor on the surface of SW403 cells increased immediately after hypotonic shock (expression on $37 \%$ of cells at time 0$)$ and remains elevated $(45 \%$ expression) up to $10 \mathrm{~h}$ (data not shown). These results further highlight that tumor cell death after $1 \mathrm{~min}$ of exposure to distilled water occurs through activation of $\mathrm{P} 2$ receptors known to be cytotoxic. In contrast P2X7 receptors were not detected in normal cells (human fibroblasts) after a challenge with either distilled water or isotonic media for $1 \mathrm{~min}$ (Figure 9b). These data support the difference between behavior of normal and tumor cells after hypotonic shock.

\section{Discussion}

ATP has an established role as the principal molecule responsible for energy storage inside cells. More recently, ATP has also been detected in nanomolar concentrations in the extracellular space where it serves as a signaling molecule. For example, ATP is a potent vasodilator ${ }^{10}$ and regulates noradrenergic, noncholinergic smooth muscle contraction ${ }^{6}$ by the peripheral nervous system. Furthermore, ADP release from platelets is an important signal-mediating thrombostasis. ${ }^{11}$ In the gastrointestinal tissue, ATP stimulates fluid and electrolyte secretion in colon, pancreatic duct and the bile ducts. ${ }^{12}$ Other functions of ATP include a paracrine role in coordinating hepatocytes and ductular components of bile formation. ${ }^{5}$ Finally, it is known since the early 1990s that extracellular ATP is a possible mediator of cell-mediated cytotoxicites $^{13}$ and can induce apoptosis in various cell types. $^{14-18}$ 
In this study, we demonstrate that volume-sensitive ATP release also occurs in colon cancer cell lines and that it functions in an autocrine/paracrine manner to initiate apoptosis. Several lines of evidence support these conclusions. Specifically, (i) hypotonic exposure stimulates ATP release, (ii) hypotonic exposure stimulates apoptosis of susceptible cells, (iii) the apoptotic response is inhibited by blockade of purinergenic signaling and reconstituted by the $\mathrm{P} 2$ receptor agonist ATP $\gamma \mathrm{S}$ and (iv) direct incubation of cells to ATP at the amount released by exposure to distilled water induces massive cell death. While these data are best explained by P2-receptor stimulation of apoptosis, additional effects of cell swelling in the induction of delayed cell death cannot be excluded.

Tumor growth is usually suppressed by the activation of the apoptotic pathway. Failure to induce apoptosis has been associated with tumor cell survival and progression of cancer. ${ }^{19}$ Understanding the mechanisms triggering apoptosis may offer therapeutic options to stimulate tumor cell destruction. Two different pathways of apoptosis have been identified. The extrinsic pathway involves the activation of caspase 8 , which directly activates downstream caspases, such as caspase 3 . The intrinsic pathway of apoptosis involves mitochondria resulting in cytochrome $c$ release and activation of the initiator caspase, caspase- 9 , with subsequent activation of effector caspases (i.e. caspase-3). ${ }^{20,21}$ The intrinsic pathway can be activated by agents that directly target the mitochondria without activation of caspase 8 . In this study, the P2-Receptor ATP interaction resulted in the activation of the second pathway including cytochrome $c$ release. Cytochrome $c$ release involves mitochondrial membrane pore formation, which can be blocked or enhanced by mitochondrial membrane proteins, such as Bcl-2, Bcl-xL, Bax, Bad etc. Thus, detection of an extracellular signal that triggers apoptosis, opens the door to modulation of this pathway in a tumor-specific manner.

The novel pathway of ATP-mediated induction of apoptosis might have clinical relevance. First, new therapeutic strategies against colon cancer could be developed based on the presence of specific P2-receptors. ATP analogues or P2-receptor agonists might exhibit antitumor effects and could be used to activate the ATP-dependent killing pathways in cancer. Second, ATP release and P2-receptor activation might be involved in T-cell mediated tumor control. Tumors with a defect in the ATP pathway might have a poorer prognosis and faster tumor progression than tumors with preserved ATP signaling. In addition, chemotherapy or radiation-induced apoptosis could be linked to a failure of ATP release or deficiency of the P2-receptors. Identifying mechanisms of resistance to chemotherapy or radiation could help predicting treatment response and offer further possibilities to overcome treatment failure.

Finally, these findings suggested that in selected situations, such as peritoneal carcinosis or pleural metastases, water itself could prove to be an effective chemotherapeutic agent with minimal side effects based on the induction of tumor cell swelling and activation of the ATP pathway. The same mechanisms might also be present in other diseases or types of injury, associated with apoptosis.
In summary, volume-sensitive ATP release and P2receptor-mediated apoptosis represent a potential pathway for induction of cell death in human colon cancer cells. Knowledge regarding the receptors and signaling pathways involved might be directly relevant for understanding tumor cell development, resistance to treatment regimens and the design of new therapeutic strategies.

\section{Materials and Methods}

\section{Cell culture}

Studies were performed using SW403, HCT 116, Colo (human colon carcinoma) cells purchased from ATCC. In additional studies, HFF5 (human fibroblasts) and primary rat hepatocytes were assessed as noncancer cells. Cells were plated at a density of $5 \times 10^{6}$ in DMEM/F12 media (SW403) containing 10\% fetal bovine serum and $1 \%$ PenicillineStreptomycin at $37^{\circ} \mathrm{C}, 5 \% \mathrm{CO}_{2}$ atmosphere or in Mc Coy's, Lebovitz 15 , MEM and Williams media (HCT 116, Colo, HFT5 and rat hepatocytes).

\section{Hypotonic stress}

After $24 \mathrm{~h}$ of culture, cells were exposed to distilled water for 1,3 or $5 \mathrm{~min}$ at $37^{\circ} \mathrm{C}$, followed by immediate restitution of usual media for $24 \mathrm{~h}$. Control studies were performed by exposure of cells for $1 \mathrm{~min}$ to different concentrations of saline solution $(0.20,0.45,0.75,0.9$ or $1.8 \%)$. Cell viability was measured by Trypan blue staining at 4,12 and $24 \mathrm{~h}$ after hypotonic stress.

\section{Reagents}

ATP $\gamma$ S was used as a P2-receptor purinergic agonist. $\mathrm{Gd}^{3}$ was utilized to inhibit ATP release. Suramin was used to block P2 receptors and apyrase to cleave extracellular ATP. All experimental reagents were obtained from Calbiochem or Sigma.

\section{Trypan blue staining}

Cells were harvested by trypsinization and stained 1:2 with a trypan blue solution (Gibco). The percentage of stained cells was determined with a Naubauer counting chamber at $\times 200$ magnification.

\section{Cell volume}

Mean SW403 cell volume was measured in cell suspension by electronic cell sizing using a Coulter Multisizer (Schaffer System). Measurements of approximately 50000 cells in suspension at intervals of $30 \mathrm{~s}$ to $1 \mathrm{~min}$ after exposure to hypotonic buffer (distilled water, 0.20 or $0.45 \%$ saline solution) were compared to basal values in control cells exposed to isotonic buffer ( $0.9 \%$ saline solution).

\section{Bioluminescence ATP detection assay}

The SW403 cells were grown to confluence in 35-mm dishes (surface area $9.62 \mathrm{~cm}^{2}$ ), washed twice with phosphate-buffered saline and incubated with Opti-MEM1 reduced serum medium plus luciferase-luciferin reagent ( $2 \mathrm{mg} / \mathrm{ml}$, lyophilized reagent from Sigma). Luminescence was measured in a Turner model TD20/20 luminometer. Since background luminescence (cells and media without luciferase-luciferin reagent) is less than 0.1 arbitrary light unit (ALU), ATP released from cells into the media which 
catalyzes the luciferase-luciferin reaction, can be determined by this assay. To induce hypotonic stress, cells were exposed to distilled water, 0.20 or $0.45 \%$ saline solution for $1 \mathrm{~min}$ followed by restitution of OptiMEM1 media. In control studies, cells were incubated for $1 \mathrm{~min}$ with $0.9 \%$ saline solution followed by restitution of Opti-MEM1. The concentration of ATP in extracellular solution was estimated by comparison of ALU values to a standard curve as described. ${ }^{7}$ These are likely to underestimate actual ATP concentration at the cell surface.

\section{TUNEL assay}

Detection of apoptosis with the TUNEL-assay was performed as previously described by Gao et al. ${ }^{22}$ Briefly, 4,12 , and $24 \mathrm{~h}$ after $1 \mathrm{~min}$ of exposure to hypotonic stress cells were fixed in freshly prepared $4 \%$ paraformaldehyde in PBS ( $\mathrm{pH} \mathrm{7.2)} \mathrm{for} 30 \mathrm{~min}$. The cells were treated with terminal deoxynucleotidyl transferase from calf thymus (Kit Boehringer) in the presence of fluorescein-dUTP and d-NTP.

\section{Annexin V assay}

Surface expression of phosphatidyl serine was determined by Annexin $V$ staining. A suspension with $10^{6}$ cells/m was exposed to Annexin $V$ and propidium iodide according to the recommendation of the manufacture (R\&D Systems Inc, Mineapolis, MN, USA). Annexin V and propidium iodide staining was determined by flow cytometry.

\section{Cytochrome $c$ release}

For analysis of cytochrome $c$ release, cells were trypsinized and washed with ice-cold PBS. Mitochondrial and cytosolic (S100) fractions were prepared from cells suspended in $50 \mu \mathrm{l}$ of ice-cold buffer containing $20 \mathrm{mmol} / \mathrm{l} \mathrm{HEPES}-\mathrm{KOH}$ (pH 7.5), $10 \mathrm{mmol} / \mathrm{KCl}, 15 \mathrm{mmol} / / \mathrm{MgCl}_{2}, 1 \mathrm{mmol} /$ I Na-EDTA, $1 \mathrm{mmol}$ (dithiothreitol, $0.1 \mathrm{mmol} / /$ phenylmethylsulfonyl fluoride, and $250 \mathrm{mmol} / /$ sucrose. Mechanical homogenization was achieved by repeated aspiration through a pipette. Cells and nuclei that were not lyzed were pelleted by $10 \mathrm{~min}$ of centrifugation $\left(750 \times \mathrm{g}, 4^{\circ} \mathrm{C}\right)$. The supernatant was centrifuged at $10000 \times g$ for $15 \mathrm{~min}$ at $4^{\circ} \mathrm{C}$. The resulting pellet, representing the mitochondrial fraction, was then resuspended in $10 \mu \mathrm{l}$ of the buffer described above. Finally, the supernatant was centrifuged at $100000 \times g$ for $1 \mathrm{~h}$ at $4^{\circ} \mathrm{C}$. Both fractions were stored at $-80^{\circ} \mathrm{C}$ until used. Mitochondrial and cytosolic fractions were diluted in sample buffer (187.5 mmol// Tris-HCl (pH 6.8), $6 \%$ SDS, $30 \%$ glycerol, $150 \mathrm{mmol} / \mathrm{I} \mathrm{DTT}$, and $0.3 \%$ bromophenol blue and then boiled for $10 \mathrm{~min}$ at $90^{\circ} \mathrm{C}$. Samples were run on $16 \%$ Novex $^{\circledR}$ Tris-Gylcine gel (Life Technologies, Inc, CA, USA) and incubated with a mouse anticytochrome $c$ monoclonal antibody (PharMingen, San Diego, CA, USA).

\section{Caspase $\mathbf{3}$ and $\mathbf{8}$ activity assay}

Caspase 3- and 8-like activity was determined by measuring the proteolysis of the specific substrate (Ac-IEDT-AFC for caspase 8 and AcDEVD-AFC for caspase 3, Biomol, Plymouth Meeting, PA, USA). ${ }^{23}$ The samples were incubated at room temperature with the specific substrate in the presence or absence of the respective inhibitor (Ac-IEDT-CHO or AcDEVD-CHO). AFC was measured over $2 \mathrm{~h}$ in a fluorometer, using $400 \mathrm{~nm}$ excitation and $505 \mathrm{~nm}$ emission filters.

\section{Detection of P2X7 receptor by flow cytometry}

The amount of P2X7 receptor on normal (HFF5) and tumoral (Sw403) cells was analyzed by flow cytometry. Briefly, $1 \times 10^{6} / \mathrm{ml}$ cells were incubated with either distilled water or isotonic solution 0.9 saline for $1 \mathrm{~min}$. After $5 \mathrm{~h}$, cells were washed with PBS containing $1 \%$ fetal bovine serum and were incubated with either anti-P2X7-FITC (Alamone Labs, Jerusalem, Israel) or with goat anti-mouse IgG -FITC (Becton Dickinson, San Diego, CA, USA) for $20 \mathrm{~min}$ at room temperature. After two washes with PBS containing $1 \%$ fetal bovine serum cells were resuspended in $300 \mu \mathrm{l}$ of staining solution and immediately analyzed by flow cytometry (FACScaliber, Becton Dickinson, San Diego, CA, USA).

\section{Statistical analysis}

Differences between two groups were analyzed using the Student's $t$-test. Multiple groups were compared using analysis of variance (ANOVA) followed by pairwise comparisons with Bonferroni's post hoc analysis. $P<0.05$ was considered significant.

\section{Acknowledgements}

This study was supported by a grant from the National Institutes of Health (DK54048-01A1 to PAC) and the Swiss National Science Foundation (SNF3200-061411 to PAC). NS is supported by grants from EMDO and Theodor and Ida Herzog-Egli, Switzerland, to NS. MS is the Novantis Transplant fellow in the Department of Visceral Surgery in Zurich.

\section{References}

1. Umpleby $H C$ and Williamson RC (1984) The efficacy of agents employed to prevent the recurrence in colorectal carcinoma. Ann. R. Coll. Surg. Engl. 66: 192-194

2. Collins S (1993) Decreasing the risk of implantation of cancer cells intraoperatively Laryngoscope 103: 825-827

3. Wang Y, Roman RM, Lidofsky SD and Fitz JG (1996) Autocrine signaling through ATP release represents a novel mechanism for cell volume regulation. Proc. Natl. Acad. Sci. USA. 93: 12020-12025

4. Feranchak AP, Roman RM, Schwiebert EM and Fitz JG (1998) Phosphatidylinositol 3-kinase contributes to cell volume regulation through effects on ATP release. J. Biol. Chem. 273: 14906-14911

5. Roman RM, Wang Y and Fitz JG (1997) Volume sensitive biliary $\mathrm{Cl}$ chanels: regulation by extracellular ATP and implications for biliary secretion. Hepatology 26: 530

6. Suprenant A (1996) Functional properties of native and cloned P2X receptors In P2 Purinoreceptors: Localization, Function and Signal Transduction Mechanism 198th edn, Chadwick DJ and Goode JA, eds Chichester, England: Wiley pp. 208-222

7. Roman RM, Feranchak AP, Davison A, Schwieberet E and Fitz JG (1999) Evidence for Gd3 inhibition of membrane ATP peremability and purinergic signaling. Am. J. Physiol. 277: G1222-G1230

8. Bortner CD and Cidlowski JA (1996) Absence of volume regulatory mechanisms contributes to the rapid activation of apoptosis in thymocytes. Am. J. Physiol. 271: C950-C961

9. Matthews CC and Feldman EC (1996) Insulin like growth factor I rescues SH-SY5Y human neuroblastoma cells from hyperosmotic induced programmed cell death. J. Cell Physiol. 166: 323-331

10. Brian J, Faraci $F$ and Heistadt D (1996) Recent insights into the regulation of cerebral circulation. Clin. Exp. Pharmacol. Physiol. 23: 449-457

11. Burnstock $G$ (1989) Vascular control by purines with emphasis on the coronary system. Eur. Heart J. 10: 15-21

12. Stutts M, Lazarowski E, Paradisio A and Boucher P (1995) Activation of CFTR $\mathrm{Cl}$ conductance in polarized T84 cells by luminal extracellular ATP. Am. J. Physiol. 288: C425-C433

13. Di Virgilio F, Bronte V, Callavo D and Zanovello P (1989) Responses of mouse lymphocytes to extracellular adenosine 5 triphosphate (ATP). Lymphocytes with cytotoxic activity are resistant to the permeabilizing effects of ATP. J. Immunol. 143: 1955-1960 
14. Di Virgilio F, Pizzo P, Zanovello P, Bronte V and Collavo D (1990) Extracellular ATP as a possible mediator of cell medaited cytotoxicity. Immuno.I Today 11: 274-277

15. Zheng LM, Zychlinsky A, Liu CC, Ojcius DM and Young J (1991) Extracellular ATP as a trigger for apoptosis of programmed cell death. J. Cell Biol. 112: 279-288

16. Tanaka Y, Yoshihara K, Tsuyuki M and Kamiya T (1994) Apoptosis induced by adenosine in human leukemia HL-60 cells. Exp. Cell Res. 213: 242-252

17. Wakade TD, Palmer KC, McCauley R, Przywara DA and Wakade AR (1995) Adenosine induced apoptosis in chick embryonic sympathetic neurons: a new physiological role for adenosine. J. Physiol. (Lond.) 488: 123-138

18. Dawicki DD, Chatterjee D, Wyche J and Rounds S (1997) Extracellular ATP and adenosine cause apoptosis of pulmonary artery endothelial cells. Am. J. Physiol. 273: L485-L489
19. Selzner M, Bielawaska A, Morse MA, Rudiger HA, Sindram D, Hannun YA and Clavien PA (2001) Induction of apoptotic cell death and prevention of tumor growth by ceramide analogues in metastatic human colon cancer. Cancer Res. 61: $1233-1240$

20. Scaffidi C, Schmitz I, Zha J, Korsmeyer SJ, Krammer PH and Peter ME (1999) Differential modulation of apoptosis sensitivity in CD95 type I and type II cells. J. Biol. Chem. 274: 22532-22538

21. Scaffidi C, Fulda S, Srinivasan A, Friesen C, Li F, Tomaselli KJ, Debatin KM, Krammer PH and Peter ME (1998) Two CD95 (APO-1/Fas) signaling pathways. EMBO J. 17: 1675-1687

22. Gao W, Bentley R, Madden J and Clavien PA (1998) Apoptosis of sinsusoidal endothelial cells is a critical mechanism of prevention injury in rat liver transplantation. Hepatology 27: 1652-1660

23. Nicholson D, Ali A and Thornebery N (1995) Identification and inhibition of the ICE/CED-3 protease necessary for mammalian apoptosis. Nature 376: 37-43 